\title{
Erythropoietin as candidate for supportive treatment of severe COVID-19
}

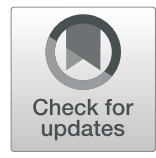

\author{
Hannelore Ehrenreich ${ }^{1 *}$ (D), Karin Weissenborn ${ }^{2}$, Martin Begemann ${ }^{1,3}$, Markus Busch ${ }^{4}$, Eduard Vieta ${ }^{5}$ and \\ Kamilla W. Miskowiak ${ }^{6 *}$
}

\begin{abstract}
In light of the present therapeutic situation in COVID-19, any measure to improve course and outcome of seriously affected individuals is of utmost importance. We recap here evidence that supports the use of human recombinant erythropoietin (EPO) for ameliorating course and outcome of seriously ill COVID-19 patients. This brief expert review grounds on available subject-relevant literature searched until May 14, 2020, including Medline, Google Scholar, and preprint servers. We delineate in brief sections, each introduced by a summary of respective COVID-19 references, how EPO may target a number of the gravest sequelae of these patients. EPO is expected to: (1) improve respiration at several levels including lung, brainstem, spinal cord and respiratory muscles; (2) counteract overshooting inflammation caused by cytokine storm/ inflammasome; (3) act neuroprotective and neuroregenerative in brain and peripheral nervous system. Based on this accumulating experimental and clinical evidence, we finally provide the research design for a double-blind placebo-controlled randomized clinical trial including severely affected patients, which is planned to start shortly.
\end{abstract}

Keywords: SARS-CoV-2; recombinant human erythropoietin, EPO, respiratory function, inflammation, cytokine storm, neuroprotection, clinical trial design

\section{Background}

The COVID-19 (coronavirus disease 2019, caused by severe acute respiratory syndrome coronavirus 2, SARS-CoV-2) pandemic has reached yet unknown dimensions and is overwhelming societies, politics, medical systems and, in particular, intensive care units. The development of vaccines is ongoing but it still requires many months to years for them to be broadly accessible. Repurposed antiviral or immunomodulatory drugs and antisera are being evaluated in numerous, rapidly started clinical trials but thus far, despite perhaps some mild positive signals and even one speedy temporary approval by FDA and EMA (https://www.nih.gov/newsevents/news-releases/nih-clinical-trial-shows-remdesivir-accelerates-recovery-advanced-covid-19; https://www.nature.com/

\footnotetext{
* Correspondence: ehrenreich@em.mpg.de; Kamilla.miskowiak@regionh.dk ${ }^{1}$ Clinical Neuroscience, Max Planck Institute of Experimental Medicine, Göttingen, Germany

${ }^{6}$ Psychiatric Centre Copenhagen, University Hospital, Rigshospitalet, Copenhagen, Denmark

Full list of author information is available at the end of the article
}

articles/d41586-020-01295-8), no clearly effective candidate has hitherto evolved. Neutralizing monoclonal antibodies against proinflammatory cytokines and their respective receptors or complement inhibitors are considered as well, but all await clinical proof-of-concept studies (Bauchner and Fontanarosa 2020; Cao 2020; Del Rio and Malani 2020; Grein et al. 2020; Lythgoe and Middleton 2020; Mehta et al. 2020a; Sanders et al. 2020). First negative trials are already reported (Casadevall et al. 2020; Li et al. 2020a; Magagnoli et al. 2020).

A substantial number of affected individuals suffer a severe disease course, with some predominance in older individuals, but serious and fatal outcomes also increasingly observed in children and young adults. The grave cases show pneumonia with severe hypoxemia, requiring oxygen supply and mechanical ventilation ( $\mathrm{Li}$ et al. 2020b; Liu et al. 2020; Mao et al. 2020; Nath 2020; Wu and McGoogan 2020; Yang et al. 2020) not infrequently combined with overshooting inflammatory reactions and a so-called 'cytokine storm' (Cao 2020; Allen et al. 2009;

(c) The Author(s). 2020 Open Access This article is licensed under a Creative Commons Attribution 4.0 International License, which permits use, sharing, adaptation, distribution and reproduction in any medium or format, as long as you give appropriate credit to the original author(s) and the source, provide a link to the Creative Commons licence, and indicate if changes were made. The images or other third party material in this article are included in the article's Creative Commons licence, unless indicated otherwise in a credit line to the material. If material is not included in the article's Creative Commons licence and your intended use is not permitted by statutory regulation or exceeds the permitted use, you will need to obtain permission directly from the copyright holder. To view a copy of this licence, visit http://creativecommons.org/licenses/by/4.0/. 
Gross et al. 2020; Liao et al. 2020; Mehta et al. 2020b; Wang et al. 2020a; Wen et al. 2020). More recently, an appreciable number of individuals with neurological complications has been identified, in particular among the severely affected subjects (Li et al. 2020b; Mao et al. 2020; Nath 2020; Avula et al. 2020; Desforges et al. 2019; Dube et al. 2018; Gandhi et al. 2020; Gu and Korteweg 2007; Helms et al. 2020; Moriguchi et al. 2020; Oxley et al. 2020; Toscano et al. 2020; Troyer et al. 2020). In the present therapeutic situation, which is essentially based on comprehensive general intensive care management, any additional measure to improve course and outcome of seriously afflicted individuals is of considerable importance. This review addresses the need and potential of symptom-targeting therapeutic measures.

\section{Introducing the candidate: recombinant human erythropoietin (EPO) - not only relevant for anemia treatment}

Erythropoietin is a hypoxia-inducible growth factor, named after its original discovery in hematopoiesis (Jelkmann 1992; Krantz 1991). Over the last 30 years, it became more and more clear that EPO is expressed in many organs and tissues of the body, where it exerts multiple functions in the sense of a pleiotropic tissue-protective cytokine. EPO has not only successfully been used to treat or prevent anemia (the approved indication) but also for various other conditions, ranging from brain to different other organ diseases, in both human trials and numerous animal studies. Overall, in critically ill patients, EPO was safe and probably efficient, as summarized in recent meta-analyses (Litton et al. 2019; Mesgarpour et al. 2017).

Extension of EPO treatment to conditions other than anemia has not been appropriately supported by industry so far, partly due to expired patents, multiple biosimilar producers, fear of off-label use and of emerging additional side effects (Sargin et al. 2010). Therefore, its beneficial properties for treating e.g. brain disease could not be sufficiently demonstrated yet by large clinical trials needed for official approval of new indications. In the present COVID-19 pandemic, we suggest short-term supportive EPO treatment of severely affected patients, which we expect to improve disease course and outcome. Although case reports always call for extreme caution, two recently published/submitted case studies on EPO in seriously ill COVID-19 patients are encouraging for the present concept (Hadadi et al. 2020; Wincewicz et al. 2020, in review). In addition, potential supportive evidence is provided by the observation that hemodialysis patients with COVID-19 are likely to experience mild disease that does not develop into fullblown pneumonia. While the authors interpret this finding as possibly due to reduced function of the immune system and decreased cytokine storm in this patient group (Perico et al. 2020), we are rather inclined to see it related to their continuous EPO treatment.

\section{Three major levels of expected beneficial EPO action on respiratory function in severely affected COVID-19 patients}

Severe acute respiratory syndrome of COVID-19 patients involves pulmonary and systemic inflammation, leading to multi-organ dysfunction in patients at high risk. Acute respiratory distress syndrome, sepsis, and acute cardiac decompensation are the most common critical complications during exacerbation. Approximately $15-33 \%$ of COVID-19 patients have severe course requiring intensive care, of whom up to $>30 \%$ need mechanical ventilation (Cao 2020; Del Rio and Malani 2020; Wu and McGoogan 2020; Goyal et al. 2020; Wang et al. 2020b). Chest radiographs are characterized by bilateral patchy infiltrates and chest computerized tomography scans demonstrate ground glass infiltrates. Histopathological findings in the lung include hyaline membrane formation, interstitial mononuclear inflammatory infiltrates, and multinucleated giant cells, findings similar to those in SARS or MERS coronavirus infections (Del Rio and Malani 2020; Munster et al. 2020). Brain invasion of SARS-CoV-2 may partially be responsible for the acute breathing failure of patients with COVID-19, with respiratory brainstem centers playing a prominent role. Associated neuropathy and myositis likely encompass phrenic nerve and respiratory muscles (Li et al. 2020b; Mao et al. 2020; Nath 2020; Lucchese and Floel 2020; Wu et al. 2020).

We propose that EPO will act on all three major levels of respiratory function in severely affected COVID-19 patients (Fig. 1). Beneficial effects of EPO on the nervous system that could contribute to improved respiration include brainstem centers and phrenic nerve. For instance, EPO in the locus coeruleus attenuates the ventilatory response to $\mathrm{CO}_{2}$ in rats, i.e. it tunes the hypercapnia-induced hyperpnoea (Silva et al. 2017). EPO-mediated regulation of the central respiratory command involves MEK $1 / 2$ and PI3K (Caravagna and Soliz 2015). These pathways are also critical for phrenic motor facilitation induced by cervical spinal EPO, indicating that it elicits spinal plasticity in respiratory motor control under conditions of prolonged or recurrent low oxygen (Dale et al. 2012).

Several reports exist demonstrating beneficial EPO effects on acute lung injury and the acute respiratory distress syndrome (ARDS) in various different animal models (reviewed in (Kakavas et al. 2011)). EPO appears to exert its pleiotropic actions in the lung by protecting the integrity of the pulmonary epithelial and endothelial cells as well as by attenuating the associated pulmonary 


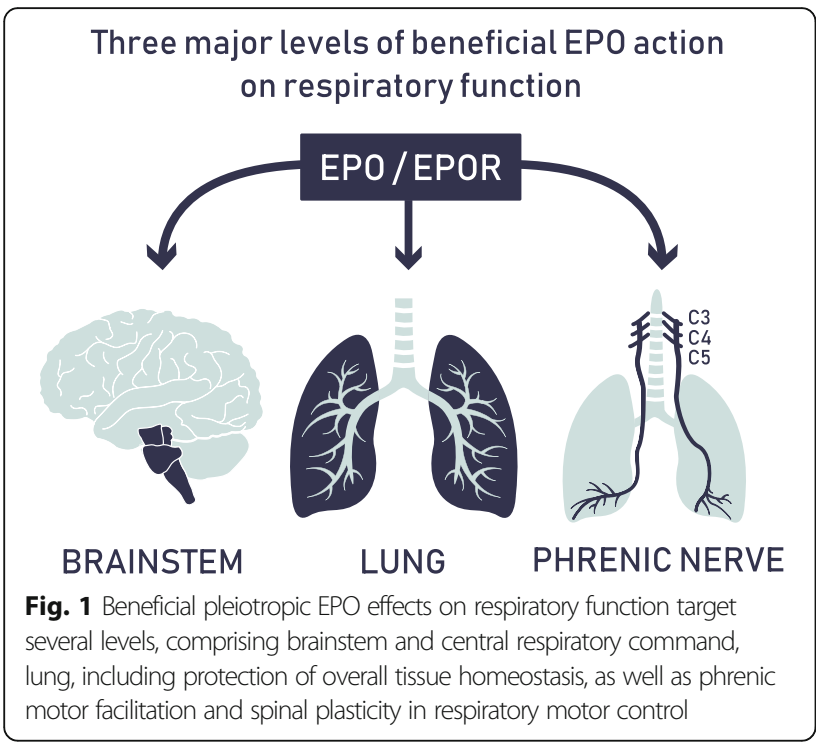

interstitial and alveolar epithelial edema and the deterioration of pulmonary oxygenation function (Kakavas et al. 2011; Zhu et al. 2019). This is achieved via modulating multiple levels of early signaling pathways involved in apoptosis, inflammation and peroxidation, potentially restoring overall homeostasis (Kakavas et al. 2011; Anagnostou et al. 1990; MacRedmond et al. 2009). Furthermore, EPO appears to confer vascular protection by promoting angiogenesis (Kakavas et al. 2011). Encouragingly, animal models of acute lung injury, consistently revealing beneficial EPO effects, comprise multiple etiologies. They include injury provoked by hyperoxia (Ozer et al. 2005), acute necrotizing pancreatitis (Tascilar et al. 2007), ischemia/reperfusion (Wu et al. 2009), sepsis induced by cecal ligation (Aoshiba et al. 2009) or by lipopolysaccharide (Shang et al. 2009), zymosan-induced non-septic shock (Cuzzocrea et al. 2006), tracheobronchial and pulmonary epithelial damage following brain trauma (Yildirim et al. 2005) and scald-burn inflammation (Rocha et al. 2015).

Data on EPO effects in human respiration are scarce. In a case of severe ARDS, lung function upon EPO improved and extracorporeal membrane oxygenation (ECMO) support could be reduced (Jungebluth et al. 2015). Intravenous EPO in volunteers exposed to mild hypoxia $\left(10 \% \mathrm{O}_{2}\right.$ for $\left.15 \mathrm{~min}\right)$ modulated the hypoxic ventilatory response. This effect appears to prevail via carotid body response, i.e. peripheral chemosensitivity, in humans as likewise seen before in mice (Soliz et al. 2009). Only marginally related, acute mountain sickness, characterized by headache, gastrointestinal symptoms, weakness, dizziness or lightheadedness, and difficulty sleeping in an unacclimatized person who recently arrived at an altitude above $2500 \mathrm{~m}$, was prevented by prophylactic EPO injections (Heo et al. 2014). Efficacy of
EPO versus placebo in critically ill patients, including those with lung disease admitted to intensive care, yielded reduction in allogeneic red blood cell transfusion. This trial did not evaluate effects on respiration, however, mortality and serious adverse events were not different between treatments, reassuring safety in pulmonary disease subjects (Silver et al. 2006).

\section{EPO to counteract inflammation and 'cytokine storm' in COVID-19}

Pneumonia, lymphopenia, lymphocyte exhaustion markers and cytokine storm characterize severe COVID19. CRP and D-dimer are abnormally high. Substantially elevated serum levels of proinflammatory cytokines, including IL-6, IL-1 $\beta$, IL-2, IL-8, IL-17, G-CSF, GM-CSF and others, contribute to shock and multi-organ damage as well as to extremely diminished numbers of CD4+ T cells, CD8+ T cells, B cells, natural killer cells, monocytes, eosinophils and basophils (Cao 2020; Liao et al. 2020; Wen et al. 2020). In addition, SARS-CoV-2 infection of $\mathrm{T}$ cells could potentially induce $\mathrm{T}$ cell apoptosis (Wang et al. 2020a).

The nucleotide-binding domain and leucine-rich repeat-containing (NLR) family of pattern-recognition molecules mediate host immunity to various viral pathogens. Experiments utilizing analogs of dsRNA (poly-I:C) and ssRNA (ssRNA40) demonstrated that an NLRP3mediated response could be activated by 'virus mimetic' RNA species (Allen et al. 2009). Whereas the NLRP3 inflammasome is an essential component in host defense against infection through sensing of viral RNA (Ivanov et al. 2020), its overshooting activity can be highly destructive. An excessive inflammatory response results in the progression of ARDS, with the NLRP3 inflammasome as key player.

Interestingly, EPO can effectively attenuate lung injury in mice by suppressing the NLRP3 inflammasome, which is dependent upon activation of EPOR/JAK2/STAT3 signaling and inhibition of the NF-kB pathway (Cao et al. 2020). This protective, balancing EPO mechanism might also be exploited for COVID-19 invasion into the brain, since in microglia, the NLRP3 inflammasome becomes (over) activated, too, when these cells sense virus. Subsequent caspase1 cleavage then markedly contributes to disease development and progression (Heneka et al. 2018).

EPO is probably in many instances of COVID-19 associated cytokine storm a better option than the ultima ratio immunosuppression (Mehta et al. 2020b), which may weaken, complicate or even endanger proper host defense. EPO suppresses proinflammatory cytokines, protects cells from apoptosis and promotes wound healing. EPO receptors (EPOR) are expressed on a variety of immune cells, enabling EPO to directly modulate their activation, differentiation and function (Peng et al. 2020; 
Suresh et al. 2019). Intriguingly, phagocyte respiratory burst activates macrophage EPO signaling to promote the resolution of acute inflammation (Luo et al. 2016). Both immunomodulation and anti-inflammation mediated by EPO promise another set of beneficial effects in severe COVID-19. In fact, combined use of EPO as antiinflammatory as well as immunomodulatory treatment and antiviral drugs may even be more effective than using either one alone. Additionally, known side effects of antiviral drugs observed in SARS include anemia, which may improve upon EPO (e.g. (Fujii et al. 2004)).

\section{EPO: the case for neuroprotection in COVID-19}

Neurologic manifestations of COVID-19 patients are increasingly reported, resemble symptoms/syndromes observed in SARS, occur most pronounced in severe cases, and range from headache, dizziness, impaired taste, smell or vision, ataxia, pain, nausea, delirium, seizures, meningoencephalitis, and impaired consciousness, to Guillain Barré syndrome, peripheral nervous system and skeletal muscle dysfunction/myositis (Mao et al. 2020; Nath 2020; Helms et al. 2020; Toscano et al. 2020; Wu et al. 2020; Baig 2020; Steardo et al. 2020). Very recently, a number of patients, many younger than 50 years, presented with radiographically confirmed acute stroke and PCR-confirmed SARS-CoV-2 infection, which emphasizes once more that neurological presentations of COVID-19 can be manifold (Avula et al. 2020; Oxley et al. 2020). Past viral pandemic-related outcomes also include neuropsychiatric symptoms, such as encephalopathy, mood changes, psychosis, or demyelinating processes, which accompanied acute viral infection or followed infection by weeks, months, or longer in recovered patients (Desforges et al. 2019; Moriguchi et al. 2020; Troyer et al. 2020; Moldofsky and Patcai 2011). Presence and persistence of human coronaviruses in human brain have been proposed to cause long-term sequelae (Troyer et al. 2020). All these observations are less surprising considering the viral spread via axons and neuron-to-neuron propagation, as known from SARS and other coronavirus infections in mammals (Dube et al. 2018; Gu and Korteweg 2007; Gu et al. 2005; Li et al. 2013; Netland et al. 2008). Coronaviruses may invade the CNS, disseminate, and participate in the induction of neurological diseases. Animal models revealed the route of neuropropagation from nasal cavity to olfactory bulb, piriform cortex and brainstem (Dube et al. 2018; Netland et al. 2008). Neurodestructive processes, including immune-mediated damage or exacerbated autoimmunity (Cao 2020; Toscano et al. 2020; Troyer et al. 2020; Lucchese and Floel 2020; Moldofsky and Patcai 2011; Lo et al. 2006; Zhang et al. 2020) may thereby well be initiated and contribute to neurodegenerative diseases like Morbus Alzheimer and other dementias as late consequences. Therefore, neuroprotective strategies should be initiated in severely affected COVID-19 patients without any delay.

EPO appears as a well-suited candidate to provide the required lasting and comprehensive neuroprotection. In the mammalian brain, EPO and EPO receptor (EPOR) expression is upregulated upon pathological conditions, e.g. brain injury of different etiologies, where it exerts anti-apoptotic, neuroprotective and neuroregenerative effects, independent of hematopoiesis (Brines and Cerami 2005; Digicaylioglu et al. 1995; Marti et al. 1996; Shingo et al. 2001). Taking an unusual reverse approach (human trials first), we reported that EPO treatment has potent neuroprotective and procognitive properties in patient groups as different as ischemic stroke, chronic schizophrenia, chronic progressive multiple sclerosis, treatment-resistant major depression and bipolar disease (Ehrenreich et al. 2007a; Ehrenreich et al. 2007b; Miskowiak et al. 2014a; Miskowiak et al. 2014b). In schizophrenia and affective disorders, we even detected in independent trials reduction of grey matter loss upon EPO (Miskowiak et al. 2015; Wustenberg et al. 2011). Animal studies performed over more than two decades confirmed these beneficial effects in a multitude of different disease models and started to provide mechanistic insight into the (patho) physiological role of the endogenous brain EPO system which includes strong effects on neurodifferentiation and neuroplasticity (Sargin et al. 2010; Sakanaka et al. 1998; Wakhloo et al. 2020). To achieve sufficiently high neuroprotective concentrations in the brain - independent of an intact or during COVID-19 potentially compromised blood-brain-barrier - high-dose intravenous EPO must be recommended as successfully used in our clinical studies on brain diseases mentioned above. To avert possible hematopoietic side effects of EPO, routine laboratory screening and - if indicated - preventive measures accompany each EPO application (for detailed description see (Bartels et al. 2008)). Taken together, EPO might have the potential to improve outcome of COVID-19 patients regarding acute as well as chronic-progressive downstream sequelae of the central and peripheral nervous system.

\section{EPO indications outside the hematopoietic system: difficult ever since - but worthwhile pursuing}

After $>20$ years of own experience in translational work on the brain EPO system, including many clinical trials, we feel that the following points need to be addressed in the context of this review and before presenting our design of a proof-of-concept trial on EPO treatment in COVID-19 below.

Work on EPO indications outside the hematopoietic system has been challenging ever since, not only because of difficulties obtaining funding as above mentioned 
briefly. We had to learn the downstream consequences of pharmaceutical companies and subsequently regulatory bodies drawing premature conclusions based on too superficially or not at all analyzed data. This did not only damage further work on EPO in stroke (Ehrenreich et al. 2009), but also influenced other EPO trials negatively (e.g. (Grasso et al. 2016)). To add to the problematic situation, studies with suboptimal trial/endpoint design despite preexisting knowledge clearly did not benefit the 'overall reputation of EPO' (Ehrenreich et al. 2020). Scientifically unfounded conclusions triggered $>10$ years ago an avalanche of destruction regarding the German EPO stroke multicenter trial where inclusion/treatment violations of stroke patients in most of the recruiting centers (totally independent of the study medication) explained the outcome rather than EPO itself (Ehrenreich et al. 2009). In fact, careful subpopulation analysis of all deceased patients revealed that several relevant baseline characteristics (i.e. data obtained before administration of any study medication) were significantly different between groups, always in disadvantage of the EPO group. For instance, upon inclusion (before study drug application), intent-to-treat non-rtPA patients receiving EPO, who died, suffered from much severer strokes as compared to placebo patients (NIHSS day 1: $20.4 \pm 5.4$ versus $13.3 \pm 4.9 ; p=0.003)$. This highly significant prediction of a worse outcome explains the twofold higher very early death rate in the EPO group (for more information, visit http://www.epo-study.de/index_eng.html).

In addition, the multicenter EPO stroke trial had to run over several years due to lack of funding in between, and exactly during this time, rtPA treatment in Germany rose dramatically (including numerous violations of rtPA indications in all but one of the trial centers). This certainly added much to the overall negative trial outcome. Importantly, we note that regarding non-rtPA patients, the originally reported benefit of EPO (Ehrenreich et al. 2002) was fully reproduced in this multicenter trial (Ehrenreich et al. 2009). In fact, not only the outcome of this non-rtPA subgroup (Ehrenreich et al. 2009) and the first EPO stroke trial (Ehrenreich et al. 2002) were promising. Also the retrospective analysis of patients only from Hannover, the most efficiently recruiting center of the multicenter EPO stroke trial, with essentially no violations of inclusion criteria and lege artis rtPA treatment, made the beneficial effect of EPO in stroke (independent of rtPA) once more obvious (Worthmann et al. 2013).

Longer treatment duration - over many weeks - may ultimately enhance the benefit of EPO for neuroprotection and neuroregeneration also after stroke. Clinical studies on EPO in chronic brain diseases (schizophrenia, multiple sclerosis, major depression and bipolar disorder) with extended treatment using high-dose EPO over many weeks showed consistently advantageous effects on cognition, motor function, and even reduction of brain matter loss (Ehrenreich et al. 2007a; Ehrenreich et al. 2007b; Miskowiak et al. 2014a; Miskowiak et al. 2014b; Miskowiak et al. 2015; Wustenberg et al. 2011). All these findings were in absence of any noticeable side effects. Therefore, in light of more and more reports on and predictions of long-term consequences of COVID19 in the sense of a virus-induced post-infection neurodegenerative course (delineated in the previous section), not only the potential for acute treatment of SARS-CoV2 by EPO, but also the substantial chance for chronic treatment might be worthwhile considering.

Of course, in all clinical EPO studies, the quality of patient care including alert follow-up of individual patients at all times is mandatory (Bartels et al. 2008; Siren et al. 2009). EPO is a potent growth factor, not a miracle drug, and it is no causal treatment or cure of brain diseases but it may improve their outcome.

\section{Design of a proof-of-concept trial on EPO treatment in COVID-19}

Based on the experimental and clinical studies on EPO summarized in the above sections, we hypothesize that EPO treatment has positive effects on clinical course and outcome of critically ill COVID-19 patients. A proof-of-concept study of EPO in COVID-19 is therefore in preparation (Fig. 2).

In this planned double-blind, placebo-controlled, randomized proof-of-concept (phase IIb) trial with safety/ futility assessment following enrollment of 20 and 40 patients, respectively, the proportion of patients with clinical improvement from WHO R\&D Blueprint ordinal scale grade 6 (hospitalized, on invasive mechanical ventilation or ECMO) to grade 5 (hospitalized, on noninvasive ventilation or high flow oxygen devices) on day 14 will be the primary outcome. EPO treatment will start as soon as the critical state requiring mechanical ventilation is reached. Secondary outcomes include COVID-19 mortality, all-cause mortality, time (days) to improve in clinical status from critical (WHO grade 6) to stable (WHO grade 5), length of hospital stay for those who recover, conversion rate of clinical status on day 7 after treatment start, duration of ECMO, duration of vasopressors, duration of oxygen therapy, SOFA score, main blood cell counts (including lymphocyte subsets via FACS), levels of CRP, LDH, D-dimer, ferritin, Il-6 and other cytokines at days 4,7 and 14 after start of treatment, as well as delta CRP, LDH, D-dimer, ferritin, Il-6 and other cytokines at days 4,7 and 14 compared to baseline at start, $\mathrm{PaO} 2 / \mathrm{FiO} 2$ ratio on days $1,2,3,4,7$ and 14 after treatment start. Blood for analyses will always be drawn before EPO/placebo injection. 


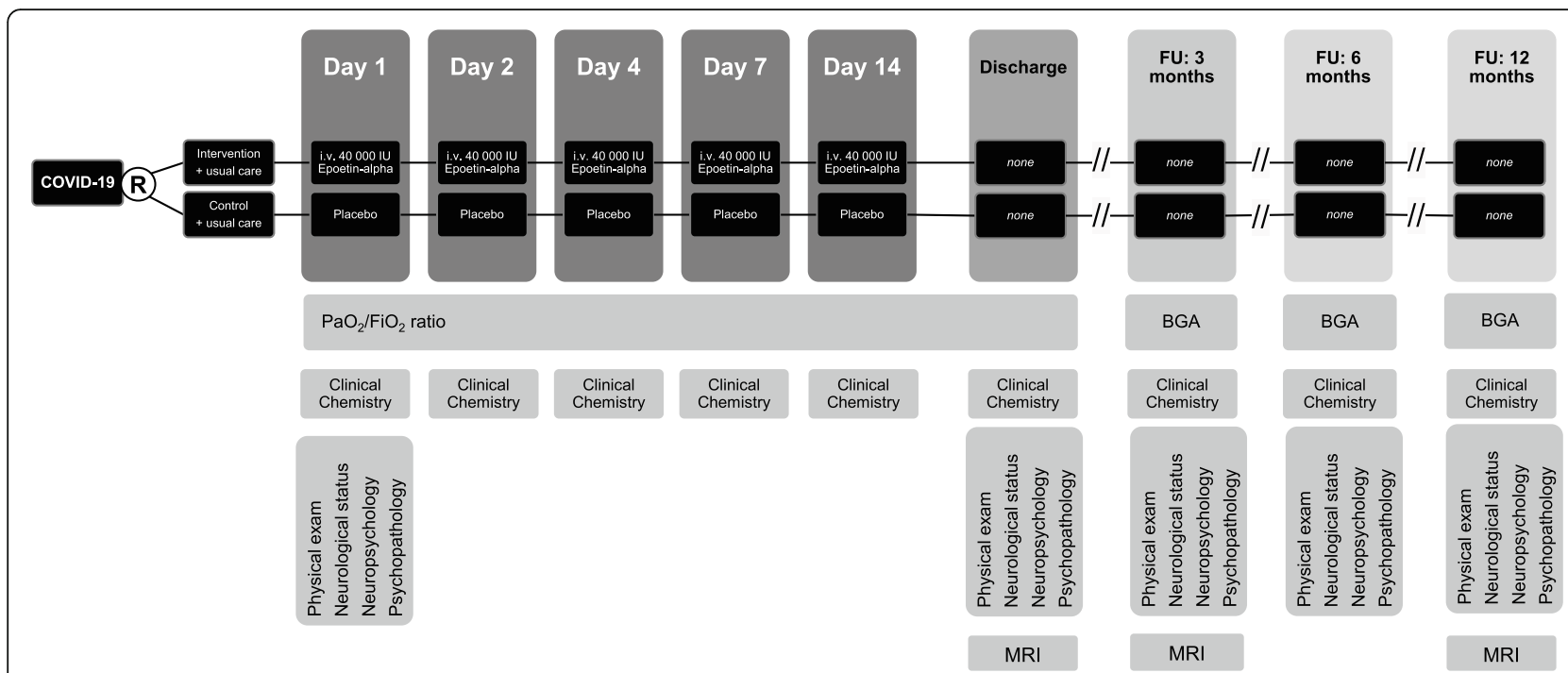

Fig. 2 Design of a double-blind, placebo-controlled, randomized proof-of-concept trial (phase IIb) on EPO treatment in severely affected COVID19 patients. Patients receive 40,000 IU recombinant human erythropoietin (EPO) or placebo plus standard care on the first day of mechanical ventilation (day 1), as well as on days 2, 4, 7 and 14. Pulmonary function and laboratory work-up including inflammatory parameters are monitored throughout in-hospital treatment, as well as on follow-up examinations at 3,6 and 12 months after discharge. At discharge and after 3 and 12 months, magnetic resonance imaging (MRI) and spectroscopy (MRS) of the brain take place. BGA = blood gas analysis, $\mathrm{FU}=$ follow-up

Inclusion criteria are SARS-CoV-2 infection confirmed by $\mathrm{PCR}$, age $>18$ years, all genders, respiratory failure $(\mathrm{PaO} 2 /$ $\mathrm{FiO} 2<300$ or $\mathrm{SatO} 2 / \mathrm{FiO} 2<220)$ demanding mechanical ventilation. Exclusion criteria are evidence of terminal chronic end organ failure (renal, cardiac, hepatic, gastrointestinal), thrombocytosis, life expectancy $\leq 24 \mathrm{~h}$, and concomitant potentially serious infections.

The intervention consists of intravenous application of recombinant human EPO (40,000 IU) or placebo at start of mechanical ventilation (day 1 ), repeated $24 \mathrm{~h}$ (day 2) and $72 \mathrm{~h}$ (day 4) later, as well as on days 7 and 14 (cumulative dose of 200,000 IU per patient). In addition, all patients receive standard intensive care anticoagulation (heparin), as anyhow strongly advisable for COVID-19 patient care (Levi et al. 2020; Paranjpe et al. 2020), and can otherwise obtain any treatment considered necessary for their clinical management.

Patients shall have follow-up examinations during their hospital stay, daily while on mechanical ventilation, and twice weekly thereafter (clinical and laboratory parameters) until discharge from hospital. Further clinical follow-up shall be performed at 3, 6 and 12 months after discharge, including assessment of pulmonary function and inflammation markers, neurological status, neuropsychological (cognitive) and psychopathological assessment, if possible combined with MRI/MRS of the brain at discharge as well as 3 and 12 months thereafter.

\section{Conclusion}

In this brief review, we address COVID-19 and the need of symptom-targeting therapeutic measures in the present pandemic situation where convincingly efficient antiviral drugs and vaccination are still absent. We present in brief chapters the major problems of severely affected COVID-19 patients and delineate the potential of EPO to relieve them. We conclude this article with a clinical research design as basis of a planned clinical trial, which is supposed to start shortly.

\section{Abbreviations}

ARDS: Acute respiratory distress syndrome; COVID-19: Coronavirus disease 2019; CRP: C-reactive protein; dsRNA: Double-stranded RNA;

ECMO: Extracorporeal membrane oxygenation; EMA: European Medicines

Agency; EPO: Erythropoietin; EPOR: Erythropoietin receptor;

FACS: Fluorescent antibody cell sorting; FDA: Food and Drug Administration; G-CSF: Granulocyte-colony stimulating factor; GM-CSF: Granulocytemacrophage colony-stimulating factor; IL: Interleukin; LDH: Lactate dehydrogenase; MERS: Middle East respiratory syndrome-related coronavirus; MRI: Magnetic resonance imaging; MRS: Magnetic resonance spectroscopy; NLR: Nucleotide-binding domain and leucine-rich repeat-containing family; $\mathrm{PaO} 2 /$ FiO2: Ratio of arterial oxygen partial pressure $(\mathrm{PaO} 2 \mathrm{mmHg}$ ) to fractional inspired oxygen (FiO2); R\&D: Research and development; rtPA: Recombinant tissue plasminogen activator; SARS: Severe acute respiratory syndrome; SARS-CoV-2: Severe acute respiratory syndrome caused by coronavirus 2; SatO2/FiO2: Ratio of oxyhemoglobin saturation in arterial blood to fractional inspired oxygen (FiO2); SOFA: Sepsis-related organ failure assessment score; ssRNA: Single-stranded RNA; WHO: World Health Organization; WHO R\&D Blueprint: Global strategy and preparedness plan that allows the rapid activation of R\&D activities during epidemics. Its aim is to fast track the availability of effective tests, vaccines and medicines that can be used to save lives and avert large-scale crisis. Classification of disease severity based on WHO R\&D Blueprint (WHO grades)

\section{Acknowledgements}

The authors thank Beata Trawinska and Gerrit Große for their help with the artwork for Figs. 1 and 2, respectively.

\section{Authors' contributions}

Concept, design and drafting of the article: HE, KWM and KW. Drafting display items: HE, KW and KWM. Literature search: HE, MBe, KWM, KW. 
Corrections and comments on the article: KWM, KW, MBe, MBu, EV. All authors read and approved the final version of the manuscript.

\section{Funding}

The Max Planck Society supported this work. KWM holds a five-year Lundbeck Foundation Fellowship (grant no. R215-2015-4121).

\section{Availability of data and materials}

Not applicable.

\section{Ethics approval and consent to participate}

Not applicable.

\section{Consent for publication}

Not applicable.

\section{Competing interests}

Authors report no conflict of interest related to this article.

\section{Author details}

${ }^{1}$ Clinical Neuroscience, Max Planck Institute of Experimental Medicine, Göttingen, Germany. ${ }^{2}$ Department of Neurology, Hannover Medical School, Hannover, Germany. ${ }^{3}$ Department of Psychiatry \& Psychotherapy, University Medical Center, Göttingen, Germany. ${ }^{4}$ Center of Internal Medicine, Hannover Medical School, Hannover, Germany. ${ }^{5}$ Institute of Neuroscience, University of Barcelona, IDIBAPS, CIBERSAM, Barcelona, Spain. ${ }^{6}$ Psychiatric Centre Copenhagen, University Hospital, Rigshospitalet, Copenhagen, Denmark.

\section{Received: 21 May 2020 Accepted: 8 June 2020}

Published online: 16 June 2020

\section{References}

Allen IC, Scull MA, Moore CB, et al. The NLRP3 inflammasome mediates in vivo innate immunity to influenza a virus through recognition of viral RNA. Immunity. 2009;30(4):556-65.

Anagnostou A, Lee ES, Kessimian N, Levinson R, Steiner M. Erythropoietin has a mitogenic and positive chemotactic effect on endothelial cells. Proc Natl Acad Sci U S A. 1990;87(15):5978-82.

Aoshiba K, Onizawa S, Tsuji T, Nagai A. Therapeutic effects of erythropoietin in murine models of endotoxin shock. Crit Care Med. 2009;37(3):889-98.

Avula A, Nalleballe K, Narula N, et al. COVID-19 presenting as stroke. Brain Behav Immun. 2020.

Baig AM. Neurological manifestations in COVID-19 caused by SARS-CoV-2. CNS Neurosci Ther. 2020;26(5):499-501.

Bartels C, Spate K, Krampe H, Ehrenreich H. Recombinant human erythropoietin: novel strategies for neuroprotective/neuro-regenerative treatment of multiple sclerosis. Ther Adv Neurol Disord. 2008;1(3):193-206.

Bauchner H, Fontanarosa PB. Randomized clinical trials and COVID-19: managing expectations. JAMA. 2020

Brines M, Cerami A. Emerging biological roles for erythropoietin in the nervous system. Nat Rev Neurosci. 2005;6(6):484-94.

Cao F, Tian X, Li Z, et al. Suppression of NLRP3 Inflammasome by erythropoietin via the EPOR/JAK2/STAT3 pathway contributes to attenuation of acute lung injury in mice. Front Pharmacol. 2020;11:306.

Cao X. COVID-19: immunopathology and its implications for therapy. Nat Rev Immunol. 2020;20(5):269-70.

Caravagna C, Soliz J. PI3K and MEK1/2 molecular pathways are involved in the erythropoietin-mediated regulation of the central respiratory command. Respir Physiol Neurobiol. 2015;206:36-40.

Casadevall A, Joyner MJ, Pirofski LA. A randomized trial of convalescent plasma for COVID-19-potentially hopeful signals. JAMA. 2020.

Cuzzocrea S, Di Paola R, Mazzon E, et al. Erythropoietin reduces the development of nonseptic shock induced by zymosan in mice. Crit Care Med. 2006;34(4): $1168-77$

Dale EA, Satriotomo I, Mitchell GS. Cervical spinal erythropoietin induces phrenic motor facilitation via extracellular signal-regulated protein kinase and Akt signaling. J Neurosci. 2012;32(17):5973-83.

Del Rio C, Malani PN. COVID-19-new insights on a rapidly changing epidemic. JAMA. 2020;323(14):1339-40.
Desforges M, Le Coupanec A, Dubeau P, et al. Human Coronaviruses and Other Respiratory Viruses: Underestimated Opportunistic Pathogens of the Central Nervous System? Viruses. 2019;12(1).

Digicaylioglu M, Bichet S, Marti HH, et al. Localization of specific erythropoietin binding sites in defined areas of the mouse brain. Proc Natl Acad Sci U S A. 1995;92(9):3717-20.

Dube M, Le Coupanec A, Wong AHM, Rini JM, Desforges M, Talbot PJ. Axonal transport enables neuron-to-neuron propagation of human coronavirus OC43. J Virol. 2018;92(17):e00404-18.

Ehrenreich $\mathrm{H}$, Fischer B, Norra C, et al. Exploring recombinant human erythropoietin in chronic progressive multiple sclerosis. Brain. 2007a;130(Pt 10):2577-88.

Ehrenreich $\mathrm{H}$, Hasselblatt M, Dembowski C, et al. Erythropoietin therapy for acute stroke is both safe and beneficial. Mol Med. 2002:8(8):495-505.

Ehrenreich $\mathrm{H}$, Hinze-Selch D, Stawicki S, et al. Improvement of cognitive functions in chronic schizophrenic patients by recombinant human erythropoietin. Mol Psychiatry. 2007b;12(2):206-20.

Ehrenreich H, Neubauer AP, Miskowiak K. Erythropoietin in preterm infants. N Engl J Med. 2020;382(19):1862.

Ehrenreich $\mathrm{H}$, Weissenborn $\mathrm{K}$, Prange $\mathrm{H}$, et al. Recombinant human erythropoietin in the treatment of acute ischemic stroke. Stroke. 2009;40(12): e647-56.

Fujii T, Nakamura T, Iwamoto A. Current concepts in SARS treatment. J Infect Chemother. 2004;10(1):1-7.

Gandhi S, Srivastava AK, Ray U, Tripathi PP. Is the collapse of the respiratory Center in the Brain Responsible for respiratory breakdown in COVID-19 patients? ACS Chem Neurosci. 2020

Goyal P, Choi JJ, Pinheiro LC, et al. Clinical characteristics of Covid-19 in New York City. N Engl J Med. 2020

Grasso G, Alafaci C, Ghezzi P. Is erythropoietin a worthy candidate for traumatic brain injury or are we heading the wrong way? F1000Res. 2016;5:911.

Grein J, Ohmagari N, Shin D, et al. Compassionate use of Remdesivir for patients with severe Covid-19. N Engl J Med. 2020.

Gross O, Moerer O, Weber M, Huber TB, Scheithauer S. COVID-19-associated nephritis: early warning for disease severity and complications? Lancet. 2020; in press.

Gu J, Gong E, Zhang B, et al. Multiple organ infection and the pathogenesis of SARS. J Exp Med. 2005;202(3):415-24.

Gu J, Korteweg C. Pathology and pathogenesis of severe acute respiratory syndrome. Am J Pathol. 2007;170(4):1136-47.

Hadadi A, Mortezazadeh M, Kolahdouzan K, Alavian G. Does recombinant human erythropoietin administration in critically ill COVID-19 patients have miraculous therapeutic effects? J Med Virol. 2020.

Helms J, Kremer S, Merdji H, et al. Neurologic features in severe SARS-CoV-2 infection. N Engl J Med. 2020.

Heneka MT, McManus RM, Latz E. Inflammasome signalling in brain function and neurodegenerative disease. Nat Rev Neurosci. 2018;19(10):610-21.

Heo K, Kang JK, Choi CM, Lee MS, Noh KW, Kim SB. Prophylactic effect of erythropoietin injection to prevent acute mountain sickness: an open-label randomized controlled trial. J Korean Med Sci. 2014;29(3):416-22.

Ivanov K, Garanina E, Rizvanov A, Khaiboullina S. Inflammasomes as Targets for Adjuvants. Pathogens. 2020;9(4).

Jelkmann W. Erythropoietin: structure, control of production, and function. Physiol Rev. 1992;72(2):449-89.

Jungebluth $\mathrm{P}$, Holzgraefe $\mathrm{B}$, Lim ML, et al. Autologous peripheral blood mononuclear cells as treatment in refractory acute respiratory distress syndrome. Respiration. 2015;90(6):481-92.

Kakavas S, Demestiha T, Vasileiou P, Xanthos T. Erythropoetin as a novel agent with pleiotropic effects against acute lung injury. Eur J Clin Pharmacol. 2011; 67(1):1-9.

Krantz SB. Erythropoietin. Blood. 1991;77(3):419-34.

Levi M, Thachil J, Iba T, Levy JH. Coagulation abnormalities and thrombosis in patients with COVID-19. Lancet Haematol. 2020; In press.

Li L, Zhang W, Hu Y, et al. Effect of convalescent plasma therapy on time to clinical improvement in patients with severe and life-threatening COVID-19: a randomized clinical trial. JAMA. 2020a.

Li YC, Bai WZ, Hashikawa T. The neuroinvasive potential of SARS-CoV2 may play a role in the respiratory failure of COVID-19 patients. J Med Virol. 2020b;92(6): $552-5$.

Li YC, Bai WZ, Hirano N, et al. Neurotropic virus tracing suggests a membranouscoating-mediated mechanism for transsynaptic communication. J Comp Neurol. 2013;521(1):203-12. 
Liao M, Liu Y, Yuan J, et al. Single-cell landscape of bronchoalveolar immune cells in patients with COVID-19. Nat Med. 2020; In press.

Litton E, Latham P, Inman J, Luo J, Allan P. Safety and efficacy of erythropoiesisstimulating agents in critically ill patients admitted to the intensive care unit: a systematic review and meta-analysis. Intensive Care Med. 2019;45(9):1190-9.

Liu W, Zhang Q, Chen J, et al. Detection of Covid-19 in children in early January 2020 in Wuhan, China. N Engl J Med. 2020;382(14):1370-1.

Lo AW, Tang NL, To KF. In: Herrington CS, Douek DC, editors. How the SARS coronavirus causes disease: host or organism? vol. 208. Chichester: Wiley; 2006. p. 142-51.

Lucchese G, Floel A. Molecular mimicry between SARS-CoV-2 and respiratory pacemaker neurons. Autoimmun Rev. 2020;102556.

Luo B, Wang J, Liu Z, et al. Phagocyte respiratory burst activates macrophage erythropoietin signalling to promote acute inflammation resolution. Nat Commun. 2016;7:12177.

Lythgoe MP, Middleton P. Ongoing clinical trials for the management of the COVID-19 pandemic. Trends Pharmacol Sci. 2020

MacRedmond R, Singhera GK, Dorscheid DR. Erythropoietin inhibits respiratory epithelial cell apoptosis in a model of acute lung injury. Eur Respir J. 2009; 33(6):1403-14.

Magagnoli JNA, Periera F, Cummings T, Hardin JW, Pharm SS, Ambati J. Outcomes of hydroxychloroquine usage in United States veterans hospitalized with Covid19. MedRxiv The preprint Server for Health Sciences. 2020.

Mao L, Jin $\mathrm{H}$, Wang M, et al. Neurologic manifestations of hospitalized patients with coronavirus disease 2019 in Wuhan, China. JAMA Neurol. 2020.

Marti $\mathrm{HH}$, Wenger $\mathrm{RH}$, Rivas LA, et al. Erythropoietin gene expression in human, monkey and murine brain. Eur J Neurosci. 1996;8(4):666-76.

Mehta P, Cron RQ, Hartwell J, Manson JJ, Tattersall RS. Silencing the cytokine storm: the use of intravenous anakinra in haemophagocytic lymphohistiocytosis or macrophage activation syndrome. Lancet Rheumatol. 2020a.

Mehta P, McAuley DF, Brown M, et al. COVID-19: consider cytokine storm syndromes and immunosuppression. Lancet. 2020b;395(10229):1033-4.

Mesgarpour B, Heidinger BH, Roth D, Schmitz S, Walsh CD, Herkner H. Harms of off-label erythropoiesis-stimulating agents for critically ill people. Cochrane Database Syst Rev. 2017;8(8):CD010969.

Miskowiak KW, Ehrenreich H, Christensen EM, Kessing LV, Vinberg M. Recombinant human erythropoietin to target cognitive dysfunction in bipolar disorder: a double-blind, randomized, placebo-controlled phase 2 trial. J Clin Psychiatry. 2014a;75(12):1347-55.

Miskowiak KW, Vinberg M, Christensen EM, et al. Recombinant human erythropoietin for treating treatment-resistant depression: a double-blind, randomized, placebo-controlled phase 2 trial. Neuropsychopharmacology 2014b;39(6):1399-408

Miskowiak KW, Vinberg M, Macoveanu J, et al. Effects of erythropoietin on hippocampal volume and memory in mood disorders. Biol Psychiatry. 2015; 78(4):270-7.

Moldofsky H, Patcai J. Chronic widespread musculoskeletal pain, fatigue, depression and disordered sleep in chronic post-SARS syndrome; a casecontrolled study. BMC Neurol. 2011;1 1(1):37.

Moriguchi T, Harii N, Goto J, et al. A first case of meningitis/encephalitis associated with SARS-Coronavirus-2. Int J Infect Dis. 2020;94:55-8

Munster V, Feldmann F, Williamson B, et al. Respiratory disease in rhesus macaques inoculated with SARS-CoV-2. Nature. 2020; In press.

Nath A. Neurologic complications of coronavirus infections. Neurology. 2020.

Netland J, Meyerholz DK, Moore S, Cassell M, Perlman S. Severe acute respiratory syndrome coronavirus infection causes neuronal death in the absence of encephalitis in mice transgenic for human ACE2. J Virol. 2008;82(15):7264-75.

Oxley TJ, Mocco J, Majidi S, et al. Large-vessel stroke as a presenting feature of Covid-19 in the young. N Engl J Med. 2020.

Ozer EA, Kumral A, Ozer E, et al. Effects of erythropoietin on hyperoxic lung injury in neonatal rats. Pediatr Res. 2005;58(1):38-41.

Paranjpe I, Fuster V, Lala A, et al. Association of Treatment Dose Anticoagulation with in-hospital survival among hospitalized patients with COVID-19. J Am Coll Cardiol. 2020.

Peng B, Kong G, Yang C, Ming Y. Erythropoietin and its derivatives: from tissue protection to immune regulation. Cell Death Dis. 2020;11(2):79.

Perico L, Benigni A, Remuzzi G. Should COVID-19 concern nephrologists? Why and to what extent? The emerging impasse of angiotensin blockade. Nephron. 2020:1-9.
Rocha J, Eduardo-Figueira M, Barateiro A, et al. Erythropoietin reduces acute lung injury and multiple organ failure/dysfunction associated to a scald-burn inflammatory injury in the rat. Inflammation. 2015;38(1):312-26.

Sakanaka M, Wen TC, Matsuda S, et al. In vivo evidence that erythropoietin protects neurons from ischemic damage. Proc Natl Acad Sci U S A. 1998; 95(8):4635-40.

Sanders JM, Monogue ML, Jodlowski TZ, Cutrell JB. Pharmacologic treatments for coronavirus disease 2019 (COVID-19): a review. JAMA. 2020.

Sargin D, Friedrichs H, El-Kordi A, Ehrenreich H. Erythropoietin as neuroprotective and neuroregenerative treatment strategy: comprehensive overview of 12 years of preclinical and clinical research. Best Pract Res Clin Anaesthesiol. 2010;24(4):573-94.

Shang Y, Li X, Prasad PV, et al. Erythropoietin attenuates lung injury in lipopolysaccharide treated rats. J Surg Res. 2009;155(1):104-10.

Shingo T, Sorokan ST, Shimazaki T, Weiss S. Erythropoietin regulates the in vitro and in vivo production of neuronal progenitors by mammalian forebrain neural stem cells. J Neurosci. 2001;21(24):9733-43.

Silva CA, Vicente MC, Tenorio-Lopes L, Soliz J, Gargaglioni LH. Erythropoietin in the locus coeruleus attenuates the ventilatory response to $\mathrm{CO} 2$ in rats. Respir Physiol Neurobiol. 2017;236:11-8.

Silver M, Corwin MJ, Bazan A, Gettinger A, Enny C, Corwin HL. Efficacy of recombinant human erythropoietin in critically ill patients admitted to a long-term acute care facility: a randomized, double-blind, placebo-controlled trial. Crit Care Med. 2006;34(9):2310-6.

Siren AL, Fasshauer T, Bartels C, Ehrenreich H. Therapeutic potential of erythropoietin and its structural or functional variants in the nervous system. Neurotherapeutics. 2009;6(1):108-27.

Soliz J, Thomsen JJ, Soulage C, Lundby C, Gassmann M. Sex-dependent regulation of hypoxic ventilation in mice and humans is mediated by erythropoietin. Am J Physiol Regul Integr Comp Physiol. 2009;296(6):R1837-46.

Steardo L, Zorec R, Verkhratsky A. Neuroinfection may contribute to pathophysiology and clinical manifestations of COVID-19; 2020. p. e13473.

Suresh S, Rajvanshi PK, Noguchi CT. The many facets of erythropoietin physiologic and metabolic response. Front Physiol. 2019;10:1534.

Tascilar O, Cakmak GK, Tekin IO, et al. Protective effects of erythropoietin against acute lung injury in a rat model of acute necrotizing pancreatitis. World J Gastroenterol. 2007;13(46):6172-82.

Toscano G, Palmerini F, Ravaglia S, et al. Guillain-Barre syndrome associated with SARS-CoV-2. N Engl J Med. 2020.

Troyer EA, Kohn JN, Hong S. Are we facing a crashing wave of neuropsychiatric sequelae of COVID-19? Neuropsychiatric symptoms and potential immunologic mechanisms. Brain, Behav Immunity. 2020.

Wakhloo D, Scharkowski F, Curto Y, et al. Functional hypoxia drives neuroplasticity and neurogenesis via brain erythropoietin. Nat Commun. 2020;11(1):1313.

Wang D, Hu B, Hu C, et al. Clinical Characteristics of 138 hospitalized patients with 2019 novel coronavirus-infected pneumonia in Wuhan, China. JAMA. 2020b;323(11).

Wang X, Xu W, Hu G, et al. SARS-CoV-2 infects T lymphocytes through its spike protein-mediated membrane fusion. Cell Mol Immunol. 2020a.

Wen W, Su W, Tang H, et al. Immune cell profiling of COVID-19 patients in the recovery stage by single-cell sequencing. Cell Discov. 2020;6:31.

Wincewicz D, Miskowiak KW, Vieta E. COVID-19: potential benefits of erythropoietin. (in review). 2020.

Worthmann H, Martens-Lobenhoffer J, Joumaah M, et al. Asymmetric dimethylarginine in response to recombinant tissue-type plasminogen activator and erythropoietin in acute stroke. Stroke. 2013;44(8):2128-33.

Wu H, Dong G, Liu H, Xu B, Li D, Jing H. Erythropoietin attenuates ischemiareperfusion induced lung injury by inhibiting tumor necrosis factor-alpha and matrix metalloproteinase-9 expression. Eur J Pharmacol. 2009;602(2-3):406-12.

Wu Y, Xu X, Chen Z, et al. Nervous system involvement after infection with COVID-19 and other coronaviruses. Brain Behav Immun. 2020.

Wu Z, McGoogan JM. Characteristics of and important lessons from the coronavirus disease 2019 (COVID-19) outbreak in China: summary of a report of 72314 cases from the Chinese Center for Disease Control and Prevention. JAMA. 2020.

Wustenberg T, Begemann M, Bartels C, et al. Recombinant human erythropoietin delays loss of gray matter in chronic schizophrenia. Mol Psychiatry. 2011; 16(1):26-36 21. 
Yang X, Yu Y, Xu J, et al. Clinical course and outcomes of critically ill patients with SARS-CoV-2 pneumonia in Wuhan, China: a single-centered, retrospective, observational study. Lancet Respir Med. 2020.

Yildirim E, Ozisik K, Solaroglu I, et al. Protective effect of erythropoietin on type II pneumocyte cells after traumatic brain injury in rats. J Trauma. 2005;58(6): $1252-8$.

Zhang Y, Xiao M, Zhang S, et al. Coagulopathy and Antiphospholipid antibodies in patients with Covid-19. N Engl J Med. 2020;382(17):e38

Zhu M, Wang L, Yang J, et al. Erythropoietin ameliorates lung injury by accelerating pulmonary endothelium cell proliferation via Janus kinase-signal transducer and activator of transcription 3 pathway after kidney ischemia and reperfusion injury. Transplant Proc. 2019;51(3):972-8.

\section{Publisher's Note}

Springer Nature remains neutral with regard to jurisdictional claims in published maps and institutional affiliations.

Ready to submit your research? Choose BMC and benefit from:

- fast, convenient online submission

- thorough peer review by experienced researchers in your field

- rapid publication on acceptance

- support for research data, including large and complex data types

- gold Open Access which fosters wider collaboration and increased citations

- maximum visibility for your research: over $100 \mathrm{M}$ website views per year

At $\mathrm{BMC}$, research is always in progress.

Learn more biomedcentral.com/submissions 